\title{
Longitudinal changes in lung hyperinflation in COPD
}

\author{
This article was published in the following Dove Press journal: \\ International Journal of COPD \\ 3 February 2017 \\ Number of times this article has been viewed
}

\author{
Jimyung Park' \\ Chang-Hoon Lee' \\ Yeon Joo Lee ${ }^{2}$ \\ Jong Sun Park ${ }^{2}$ \\ Young-Jae $\mathrm{Cho}^{2}$ \\ Jae Ho Lee ${ }^{2}$ \\ Choon-Taek Lee ${ }^{2}$ \\ Ho II Yoon ${ }^{2}$

\section{On behalf of the Korean \\ Obstructive Lung Disease (KOLD) Study Group} \\ 'Division of Pulmonary and Critical \\ Care Medicine, Department of \\ Internal Medicine, Seoul National \\ University Hospital, Seoul, ${ }^{2}$ Division \\ of Pulmonary and Critical Care \\ Medicine, Department of Internal \\ Medicine, Seoul National University \\ Bundang Hospital, Seongnam-Si, \\ South Korea
}

Correspondence: Ho II Yoon

Division of Pulmonary and Critical Care Medicine, Department of Internal Medicine, Seoul National University Bundang Hospital, 82, Gumi-ro 173 Beon-gil, Bundang-gu, Seongnam-Si, Gyeonggi-Do 13620, South Korea

Tel +82317877036

Fax +82 31 7874052

Email dextro@snubh.org
Purpose: COPD is characterized by an accelerated and progressive decline in forced expiratory volume in 1 second $\left(\mathrm{FEV}_{1}\right)$ and lung hyperinflation. Although lung hyperinflation is the hallmark of COPD, data on the longitudinal changes in lung hyperinflation and any association with the decline in $\mathrm{FEV}_{1}$ are lacking. The aim of this study was to evaluate the longitudinal changes in lung hyperinflation and to investigate its relationship with $\mathrm{FEV}_{1}$ decline.

Patients and methods: We conducted a prospective cohort study and studied 176 COPD patients with annual lung volume measurements over a period of 5 years or more. We used a random coefficient model to calculate the annual changes in lung volumes and to evaluate the factors associated with changes in lung hyperinflation. Additionally, the relationship between the change in lung hyperinflation and $\mathrm{FEV}_{1}$ was assessed.

Results: Residual volume (RV), inspiratory capacity (IC), and total lung capacity (TLC) declined at a mean rate of 39.5, 49.6, and $63.8 \mathrm{~mL} /$ year, respectively. While IC/TLC declined at $0.70 \%$ /year, RV/TLC also declined at $0.35 \%$ /year. Changes in both IC/TLC and RV/TLC varied significantly. Frequent exacerbations led to an increase in RV/TLC and faster decline in IC/TLC over time. RV/TLC declined in 59.7\% and increased in $40.3 \%$ of the patients. A significant negative correlation was found between the rates of change in $F_{1} V_{1}$ and $R V /$ TLC, and the rate of decline in $\mathrm{FEV}_{1}$ was greater in patients with an increase in RV/TLC than in those with a decline in RV/TLC (54.2 vs $10.7 \mathrm{~mL} /$ year, $P<0.001)$.

Conclusion: The rate of change in lung hyperinflation varied greatly among COPD patients. Progression of hyperinflation was associated with frequent exacerbations and a faster decline in $\mathrm{FEV}_{1}$.

Keywords: pulmonary disease, chronic obstructive, lung volume measurements, forced expiratory volume, cohort studies

\section{Introduction}

COPD is a chronic respiratory disease that is characterized by an airflow limitation that is not fully reversible. ${ }^{1}$ It is a leading cause of morbidity and mortality worldwide. ${ }^{2}$ Since the 1970s, it has been widely accepted that COPD patients show an accelerated and progressive decline in forced expiratory volume in 1 second $\left(\mathrm{FEV}_{1}\right){ }^{3}$ Nevertheless, recent studies have revealed that the rate of decline in $\mathrm{FEV}_{1}$ varies among individual patients. $^{4,5}$

Another important feature of COPD is lung hyperinflation, which is caused by emphysematous parenchymal destruction and expiratory flow limitation. ${ }^{6}$ It has been shown that lung hyperinflation contributes to symptoms, exercise intolerance, acute exacerbations, and mortality. ${ }^{7-9}$ Although some studies assessed the rate of decline in $\mathrm{FEV}_{1}$, data illustrating the process of lung hyperinflation development and progression over time are rare..$^{1,3-5,10}$ 
Although it is assumed that lung hyperinflation may progress as $\mathrm{FEV}_{1}$ declines over time, the longitudinal changes in lung volumes have not been studied in detail. Additionally, the relationship between the changes in the degree of lung hyperinflation and the decline in $\mathrm{FEV}_{1}$ is not clear. Thus, we evaluated the longitudinal changes in the degree of lung hyperinflation and the determinants of this change in COPD patients. In addition, we attempted to explore the relationship between the rate of change in lung hyperinflation and the rate of decline in $\mathrm{FEV}_{1}$.

\section{Materials and methods}

\section{Study patients}

Patients were selected from the Korean Obstructive Lung Disease (KOLD) cohort, a prospective longitudinal observational study consisting of patients with COPD or asthma recruited from 17 hospitals in South Korea since 2005. The inclusion and exclusion criteria for participation in the KOLD cohort have previously been described. ${ }^{11}$ For this study, we selected only COPD patients who had been followed up with annual lung volume measurements for 5 years or more. In these patients, COPD was diagnosed according to the Global Initiative for Chronic Obstructive Lung Disease (GOLD) guideline. ${ }^{12}$ All patients provided written informed consent before enrollment. The study protocol was approved by the institutional review boards of Seoul National University Hospital (H-0505-148-013), Seoul National University Bundang Hospital (B-0508/023-009), and all other participating centers.

\section{Study assessments}

The evaluation and follow-up of patients in the KOLD cohort have been previously described. ${ }^{11,13}$ Patients underwent spirometry with a bronchodilator test and measurement of lung volume on an annual basis. Spirometry with a bronchodilator test was performed according to the recommendations of the American Thoracic Society (ATS) and the European Respiratory Society (ERS), using the Vmax 22 (SensorMedics, Yorba Linda, CA, USA) or PF/DX (MedGraphics, Saint Paul, MN, USA).${ }^{14}$ Patients were asked not to use any longacting bronchodilators in the 12 hours prior to testing. ${ }^{14}$

Measurement of lung volume was conducted according to the recommendations of the ATS and ERS. ${ }^{15}$ Body plethysmography, V6200 (SensorMedics) or PF/DX (MedGraphics), was used for lung volume measurement. Lung volume measurement was performed before the administration of a bronchodilator. ${ }^{15}$ Briefly, functional residual capacity (FRC) was measured while patients were performing a series of panting maneuvers against a closed shutter. Following this, the shutter was opened and patients were instructed to perform an expiratory reserve volume maneuver, followed by slow inspiratory vital capacity (VC) maneuver. These sequential procedures enabled the calculation of residual volume (RV) and total lung capacity (TLC). ${ }^{16}$

The percentage of the predicted values for the results of spirometry was calculated from equations developed with representative Korean populations. ${ }^{17}$ As for lung volumes, the prediction equation from the European Community for Steel and Coal was used, since it was shown to be the most suitable for Korean populations. ${ }^{18,19}$ A quality assurance program was conducted to improve the reliability of pulmonary function tests when this cohort study was initiated.

After enrollment, the respective physicians from each center treated patients and advised them to participate in the follow-up visits every 3 months. At each follow-up, patients reported any exacerbations. Exacerbations were defined as an event of aggravation of COPD symptoms (ie, sputum, cough, or dyspnea) beyond normal day-to-day variations, according to the GOLD guideline..$^{20}$ In particular, severe exacerbations were defined as those leading to hospitalization, and two or more exacerbations per year on average were defined as frequent exacerbations. ${ }^{21}$

\section{Statistical analysis}

Data were presented as mean with standard deviations (SDs) for continuous variables with normal distribution or medians with interquartile ranges (IQRs) for those with non-normal distribution. Differences between subgroups were analyzed using the Student's $t$-test, Mann-Whitney test, Pearson's chisquare test, or Fisher's exact test, as appropriate. A $P$-value of $<0.05$ based on a two-tailed test was considered statistically significant.

Mixed-effect linear regressions were used for longitudinal analysis. ${ }^{22}$ To eliminate the effects of immediate improvements in patients who began treatment after enrollment, the data used for analysis were collected since 1 year after the study entry. Therefore, lung function parameters obtained at 1 year after enrollment were regarded as baseline in statistical analysis. The mean annual rates of change in RV, TLC, inspiratory capacity (IC), VC, and their ratios were estimated with a random intercept and a random slope model, using multiple covariates: baseline age, sex, smoking history, body mass index (BMI), GOLD stage according to $\mathrm{FEV}_{1}$, diffusing capacity, exacerbations, and respiratory medications. To determine the effect of covariates on the annual rates of change in RV/TLC and IC/TLC, the interaction of 
each covariate with time was assessed. Additionally, the rate of change in $\mathrm{FEV}_{1}$ over time was determined with the same method.

The best linear unbiased predictions of random effects were calculated to estimate the annual rates of change in

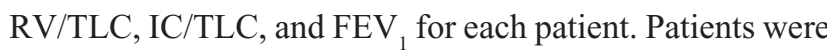
divided into two subgroups according to the mean annual rate of change in RV/TLC using a cut-off of zero: patients with an increasing RV/TLC over time (change in RV/TLC $\geq 0$ ) and those with a decreasing RV/TLC over time (change in $\mathrm{RV} / \mathrm{TLC}<0$ ). The rate of change in $\mathrm{FEV}_{1}$ was then compared between these two subgroups. For the sensitivity analysis, we repeated this comparison after dividing patients into three subgroups: those with a decreasing RV/TLC, a stable $\mathrm{RV} / \mathrm{TLC}$, or an increasing RV/TLC. Statistical analyses were carried out using STATA software version 14.0 (StataCorp, College Station, TX, USA).

\section{Results}

\section{Patient characteristics}

A total of 176 patients were analyzed for this study. The median number of lung volume measurements in each patient was seven ( 5 in 46, 6 in 35, 7 in 39, 8 in 31, 9 in 22, and 10 in three patients). The baseline characteristics of the patients are summarized in Table 1. Most of the study patients were men, with a mean age of 65 years. The mean post-bronchodilator $\mathrm{FEV}_{1}$ was $64.0 \pm 17.6 \%$ of the predicted value. No difference was found in the baseline $\mathrm{FEV}_{1}$ according to the number of lung volume measurements.

Baseline results of lung volume measurement are described in Table 2. The mean values of RV/TLC and IC/ TLC were $44.7 \pm 11.2 \%$ and $34.2 \pm 7.7 \%$, respectively. At baseline measurement, RV/TLC showed a strong negative correlation with post-bronchodilator $\mathrm{FEV}_{1}$ (Figure 1; $r=-0.644$, $P<0.001)$. IC/TLC also showed a significant correlation with post-bronchodilator $\mathrm{FEV}_{1}(r=0.541, P<0.001)$.

\section{Exacerbations during follow-up}

Patients were treated by attending physicians at each participating center; this study did not provide any guidance on management. Among the 176 patients, 137 patients (77.8\%) and 125 patients $(71.0 \%)$ were prescribed long-acting beta agonists and long-acting muscarinic antagonists, respectively. Ninety patients $(51.1 \%)$ used both long-acting beta agonists and long-acting muscarinic antagonists. Inhaled corticosteroids were prescribed for 137 patients $(77.8 \%)$, and most of these were combined with long-acting beta agonists as fixed-dose combinations.
Table I Baseline patient characteristics

\begin{tabular}{|c|c|}
\hline Characteristics & Value \\
\hline Age, years & $65 \pm 7$ \\
\hline Male sex, n (\%) & $166(94.3)$ \\
\hline $\mathrm{BMI}, \mathrm{kg} / \mathrm{m}^{2}$ & $23.5 \pm 3.3$ \\
\hline \multicolumn{2}{|l|}{ Smoking status } \\
\hline Current smoker, n (\%) & $54(30.7)$ \\
\hline Smoking history, pack-year & $42.0(25.0,54.0)$ \\
\hline \multicolumn{2}{|c|}{ Exacerbations during the year prior to enrollment } \\
\hline Experience of exacerbation, $\mathrm{n}(\%)$ & $30(17.1)$ \\
\hline Frequency of exacerbation & $2(1,5)$ \\
\hline mMRC dyspnea scale & $2(1,2)$ \\
\hline SGRQ score & $28.76(20.43,4 I .7 I)$ \\
\hline 6MWD, m & $456.8 \pm 74.2$ \\
\hline \multicolumn{2}{|l|}{ Post-bronchodilator FEV } \\
\hline Value, L & $1.70 \pm 0.53$ \\
\hline Percentage of predicted value & $64.0 \pm 17.6$ \\
\hline \multicolumn{2}{|l|}{ Post-bronchodilator FVC } \\
\hline Value, L & $3.45 \pm 0.78$ \\
\hline Percentage of predicted value & $92.5 \pm 17.7$ \\
\hline Post-bronchodilator FEV/FVC, \% & $49.3 \pm 10.2$ \\
\hline \multicolumn{2}{|l|}{ GOLD stage } \\
\hline $\mathrm{I}, \mathrm{n}(\%)$ & $34(19.3)$ \\
\hline II, n (\%) & $106(60.2)$ \\
\hline III, n (\%) & $33(18.8)$ \\
\hline IV, n (\%) & $3(1.7)$ \\
\hline \multicolumn{2}{|l|}{ DLCO } \\
\hline Value, $\mathrm{mL} / \mathrm{mmHg} / \mathrm{min}$ & $16.15 \pm 6.00$ \\
\hline Percentage of predicted value & $84.9 \pm 25.7$ \\
\hline
\end{tabular}

Notes: Data are shown as mean \pm SD for normally distributed data, medians (with IQRs) for non-normally distributed data, and number (\%) for categorical variables. Abbreviations: BMI, body mass index; mMRC, modified Medical Research Council; SGRQ, St George's Respiratory Questionnaire; 6MWD, 6-minute walk distance; $\mathrm{FEV}_{\text {, }}$, forced expiratory volume in I second; FVC, forced vital capacity; GOLD, Global Initiative for Chronic Obstructive Lung Disease; DLCO, diffusing capacity for carbon monoxide; SD, standard deviation; IQR, interquartile range.

Table 2 Results of baseline lung volume measurement

\begin{tabular}{ll}
\hline Parameters & Value \\
\hline RV & \\
$\quad$ Value, $L$ & $2.80 \pm 0.96$ \\
$\quad$ Percentage of predicted value & $131.8 \pm 44.3$ \\
FRC & \\
$\quad$ Value, $L$ & $4.10 \pm 0.98$ \\
$\quad$ Percentage of predicted value & $128.1 \pm 27.2$ \\
TLC & \\
$\quad$ Value, $L$ & $6.21 \pm 1.09$ \\
$\quad$ Percentage of predicted value & $112.7 \pm 16.9$ \\
IC & \\
$\quad$ Value, $L$ & $2.10 \pm 0.53$ \\
$\quad$ Percentage of predicted value & $83.4 \pm I 8.8$ \\
VC & \\
$\quad$ Value, L & $3.40 \pm 0.75$ \\
$\quad$ Percentage of predicted value & $92.9 \pm 16.8$ \\
IC/TLC ratio, \% & $34.2 \pm 7.7$ \\
RV/TLC ratio, \% & $44.7 \pm I I .2$ \\
VC/TLC ratio, \% & $55.3 \pm I I .2$ \\
\hline
\end{tabular}

Notes: Data are shown as mean \pm SD.

Abbreviations: RV, residual volume; FRC, functional residual capacity; TLC, total lung capacity; IC, inspiratory capacity; VC, vital capacity; SD, standard deviation. 


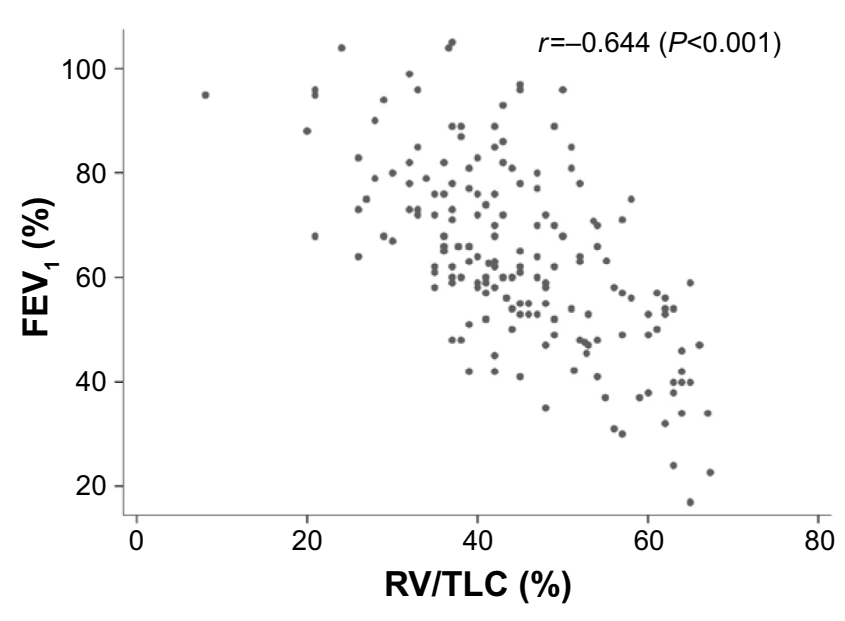

Figure I Correlation between the RV/TLC ratio and the percentage of predicted value of post-bronchodilator FEV at baseline measurement.

Abbreviations: RV, residual volume; TLC, total lung capacity; $\mathrm{FEV}_{1}$, forced expiratory volume in I second.

The median follow-up period was 7 years (IQR 5-8 years). During this time, 155 patients $(88.1 \%)$ experienced at least one exacerbation and 44 patients $(25.0 \%)$ experienced severe exacerbations requiring hospitalization. In each patient, the median number of exacerbations per year was 0.7 (IQR 0.2-1.4). Twenty-seven patients (15.3\%) had frequent exacerbations (two or more exacerbations per year on average). When compared to patients with infrequent exacerbations, those with frequent exacerbations had a significantly lower post-bronchodilator $\mathrm{FEV}_{1}(1.42 \pm 0.47$ vs $1.75 \pm 0.52 \mathrm{~L}, P=0.003)$ at baseline. As for indices of lung hyperinflation, patients with frequent exacerbations had significantly higher RV $(3.20 \pm 1.12$ vs $2.73 \pm 0.92 \mathrm{~L}, P=0.018)$ and RV/TLC (49.3 $\pm 9.9 \%$ vs $43.8 \pm 11.2 \%, P=0.018)$.

\section{Longitudinal changes in lung hyperinflation}

In the longitudinal analysis of lung volumes, a decline in the mean rates of change in $\mathrm{RV}, \mathrm{VC}$, and TLC over time (39.5, 24.2, and $63.8 \mathrm{~mL} /$ year, respectively) was noted. The between-subjects SD values for the rate of change in $\mathrm{RV}$, VC, and TLC were 130.6, 52.6, and $106.9 \mathrm{~mL} /$ year, respectively. The mean rate of change in IC was also a decline of $49.6 \mathrm{~mL} /$ year. In order to adjust for the change in TLC, annual rates of change in $\mathrm{RV} / \mathrm{TLC}, \mathrm{VC} / \mathrm{TLC}$, and IC/TLC were analyzed. While the IC/TLC ratio declined by an average of $0.70 \% / y e a r$, the RV/TLC ratio tended not to increase but

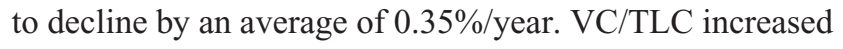
by an average of $0.36 \% / y e a r$, which reflects the decline in $\mathrm{RV} / \mathrm{TLC}$ over time.

On an individual level, the annual rates of change in RV/TLC and IC/TLC varied significantly (Figures 2 and 3).

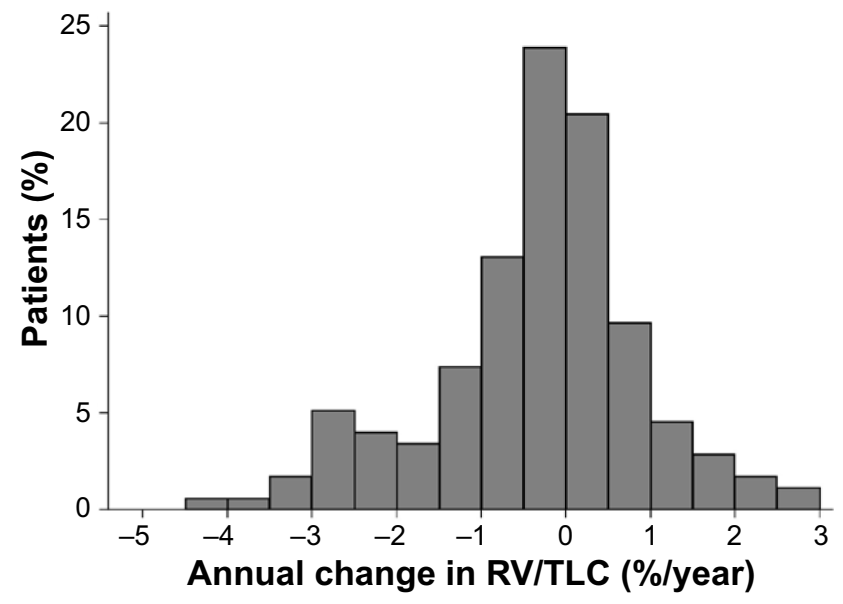

Figure 2 Distribution of estimated annual rate of change in the RV/TLC ratio. Abbreviations: RV, residual volume; TLC, total lung capacity.

In 71 patients (40.3\%), RV/TLC increased over time, and in 105 patients (59.7\%), RV/TLC decreased over time. No significant differences were found in baseline pulmonary function parameters between these two subgroups. During the follow-up period, frequent exacerbations were significantly more common in patients with an increasing RV/TLC over time than in those with a decreasing RV/TLC over time $(22.5 \%$ vs $10.5 \%, P=0.029)$. We also compared the annual rates of change in $\mathrm{RV}, \mathrm{VC}$, and TLC between patients with an increasing RV/TLC and those with a decreasing RV/TLC and found significant differences (all $P<0.001$ ). In 71 patients who showed an increase in RV/TLC over time, the mean annual rates of change in RV and TLC were increases of 93.6 and $19.7 \mathrm{~mL} /$ year, respectively. However, in 105 patients who showed a decline in RV/TLC over time, both RV and TLC showed a decrease at a rate of 143.7 and $128.9 \mathrm{~mL} /$ year, respectively. $\mathrm{VC}$ decreased by $78.0 \mathrm{~mL} /$ year in patients with

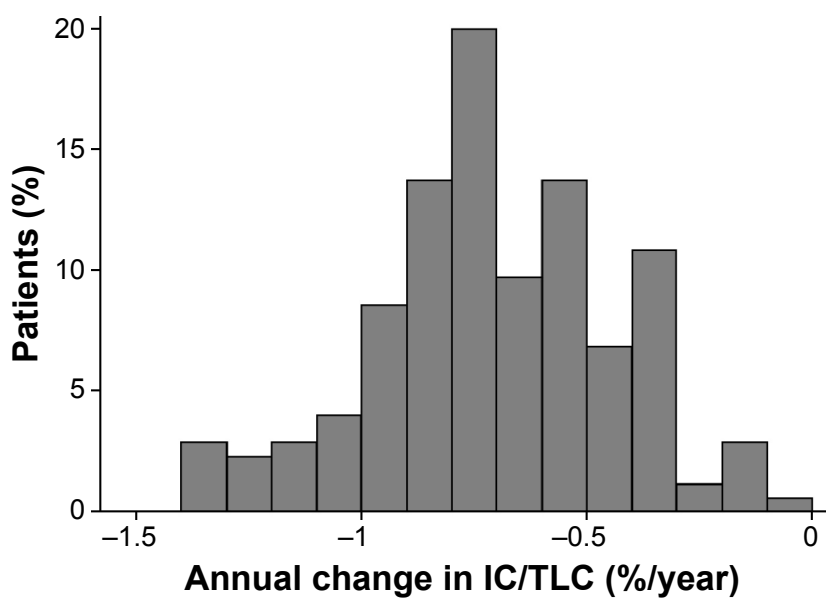

Figure 3 Distribution of estimated annual rate of change in the IC/TLC ratio. Abbreviations: IC, inspiratory capacity; TLC, total lung capacity. 
Table 3 Effect of exacerbation and treatment on the change in RV/TLC ratio and IC/TLC ratio

\begin{tabular}{|c|c|c|c|c|}
\hline Characteristics & $\begin{array}{l}\text { Adjusted annual rate } \\
\text { of change in } R V / T L C\end{array}$ & $P$-value & $\begin{array}{l}\text { Adjusted annual rate } \\
\text { of change in IC/TLC }\end{array}$ & $P$-value \\
\hline $\begin{array}{l}\text { Exacerbations during the year prior to } \\
\text { enrollment }\end{array}$ & & 0.083 & & 0.261 \\
\hline No $(n=146)$ & $-0.48 \pm 0.18$ & & $-0.75 \pm 0.11$ & \\
\hline Yes $(n=30)$ & $0.3 I \pm 0.42$ & & $-0.44 \pm 0.25$ & \\
\hline Exacerbations during follow-up & & 0.007 & & 0.014 \\
\hline Infrequent (<2/year; $\mathrm{n}=\mid 49)$ & $-0.54 \pm 0.18$ & & $-0.59 \pm 0.11$ & \\
\hline Frequent ( $\geq 2 /$ year; $n=27$ ) & $0.67 \pm 0.4 I$ & & $-1.21 \pm 0.23$ & \\
\hline Use of long-acting beta agonist & & 0.666 & & 0.582 \\
\hline No $(n=39)$ & $-0.48 \pm 0.36$ & & $-0.59 \pm 0.22$ & \\
\hline Yes $(n=137)$ & $-0.3 I \pm 0.19$ & & $-0.73 \pm 0.11$ & \\
\hline Use of long-acting muscarinic antagonist & & 0.440 & & 0.002 \\
\hline No $(n=5 I)$ & $-0.14 \pm 0.32$ & & $-0.21 \pm 0.19$ & \\
\hline Yes $(n=125)$ & $-0.43 \pm 0.20$ & & $-0.89 \pm 0.12$ & \\
\hline Use of inhaled corticosteroid & & 0.694 & & 0.545 \\
\hline No $(n=39)$ & $-0.48 \pm 0.36$ & & $-0.58 \pm 0.22$ & \\
\hline Yes $(n=137)$ & $-0.31 \pm 0.19$ & & $-0.73 \pm 0.11$ & \\
\hline
\end{tabular}

Notes: Data are shown as mean \pm standard error. Mixed-effect linear regression analysis was performed, which included the following covariates: age, sex, current smoking status, smoking pack-year, exacerbations before and after enrollment, BMI, GOLD stage, diffusing capacity, treatments, and interaction of each covariate with time.

Abbreviations: RV, residual volume; TLC, total lung capacity; IC, inspiratory capacity; BMI, body mass index; GOLD, Global Initiative for Chronic Obstructive Lung Disease.

an increasing RV/TLC, and it increased by $16.9 \mathrm{~mL} /$ year in those with a decreasing RV/TLC.

Baseline demographic characteristics, smoking history, and pulmonary function had no significant effect on the annual rates of change in RV/TLC and IC/TLC. However, the exacerbations were significantly associated with the annual rates of change in these parameters (Table 3 ). Frequent exacerbations were significantly associated with the progression of hyperinflation in terms of both $\mathrm{RV} /$ TLC and IC/TLC. The rate of change in RV/TLC differed significantly between patients with frequent exacerbations and those with infrequent exacerbations $(0.67 \pm 0.41 \%$ year vs $-0.54 \pm 0.18 \% /$ year, $P=0.007)$. Furthermore, patients with frequent exacerbations showed a greater decline in IC/TLC $(-1.21 \pm 0.23 \% /$ year vs $-0.59 \pm 0.11 \% /$ year, $P=0.014)$.

Treatment with different types of inhalers did not influence the rate of change in RV/TLC. None of the inhalers, including long-acting beta agonists, long-acting muscarinic antagonists, and inhaled corticosteroids, reduced the rate of decline in IC/TLC. In fact, patients who were prescribed long-acting muscarinic antagonists tended to have a faster decline in IC/TLC $(P=0.002)$.

\section{Relationship between lung volume change and $\mathrm{FEV}$, decline}

In the total study group, the mean rate of decline in $\mathrm{FEV}_{1}$ was $29.4 \pm 3.4 \mathrm{~mL} /$ year, and the between-subjects $\mathrm{SD}$ was $30.6 \mathrm{~mL} /$ year. When the rate of $\mathrm{FEV}_{1}$ decline was compared according to the rate of change in RV/TLC, there was a significant difference in the $\mathrm{FEV}_{1}$ decline rate relative to the change in RV/TLC over time, even after adjusting for other covariates. Patients with an increasing RV/TLC had a $\mathrm{FEV}_{1}$ decline rate of $54.2 \pm 4.5 \mathrm{~mL} /$ year. In contrast, the rate of $\mathrm{FEV}_{1}$ decline in patients with a decreasing $\mathrm{RV} / \mathrm{TLC}$ was $10.7 \pm 3.9 \mathrm{~mL} /$ year, which was significantly slower $(P<0.001)$. Additionally, we evaluated the correlation between the annual rates of change in $\mathrm{FEV}_{1}$ and $\mathrm{RV} / \mathrm{TLC}$ in each patient. A significant negative correlation was detected between the two (Figure $4 ; r=-0.535, P<0.001$ ). For the sensitivity analysis, we regrouped the patients into three subgroups: 63 patients

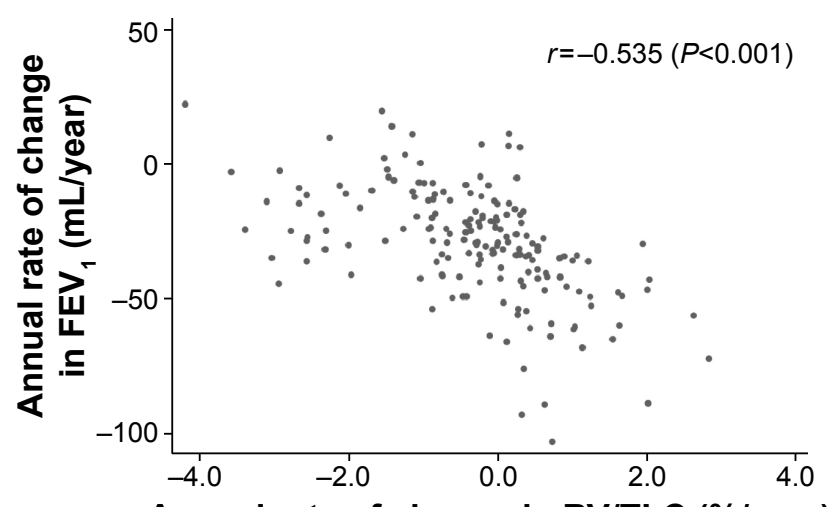

Annual rate of change in RV/TLC (\%/year)

Figure 4 The negative correlation between the rates of change in FEV, and RV/ TLC ratio.

Abbreviations: $\mathrm{FEV}_{1}$, forced expiratory volume in I second; RV, residual volume; TLC, total lung capacity. 
showed a decline in RV/TLC over time (annual rate of change in RV/TLC $<-0.5 \%$ /year; group 1), 78 patients showed a stable $\mathrm{RV} / \mathrm{TLC}$ over time $(-0.5 \% /$ year $\leq$ annual rate of change in RV/TLC $<0.5 \% /$ year; group 2 ), and 35 patients showed an increase in RV/TLC over time (annual rate of change in $\mathrm{RV} / \mathrm{TLC} \geq 0.5 \%$ /year; group 3 ). The rate of $\mathrm{FEV}_{1}$ decline was $6.3 \pm 4.9 \mathrm{~mL} /$ year in group $1,29.6 \pm 4.3 \mathrm{~mL} /$ year

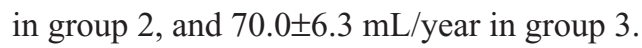

\section{Discussion}

Lung hyperinflation is a key feature of COPD, but data regarding the longitudinal change in lung hyperinflation have been scarce. Our study has revealed several interesting findings regarding lung hyperinflation. First, the lung volumes of COPD patients did not increase progressively over time. Second, a discrepancy was found in the rate of change in RV/TLC and IC/TLC. While IC/TLC declined over time, the mean trend of RV/TLC was not toward an increase. Third, the rates of change in RV/TLC and IC/TLC, as markers of static hyperinflation, varied greatly between patients. Unexpectedly, more than half of the patients showed a gradual decline in RV/TLC. Finally, patients who had an increase in RV/TLC over time showed a significantly greater decline in $\mathrm{FEV}_{1}$. To our knowledge, this is the first study to show the association between changes in lung hyperinflation and changes in $\mathrm{FEV}_{1}$.

Although there has been increasing interest in lung hyperinflation in COPD patients, no single standardized marker or criterion for hyperinflation has been established to date. Dynamic hyperinflation is usually assessed by measuring IC repetitively during exercise. ${ }^{23-25}$ However, there is no consensus on the method to define and measure static hyperinflation. ${ }^{26}$ Recently, a few studies have used IC at resting state as an indicator of static hyperinflation, since it correlated well with subjective dyspnea, exercise intolerance, and mortality in COPD patients. ${ }^{8,27,28}$ However, using only IC for defining static hyperinflation has limitations. Patients with mild airway obstruction and a hyperinflated RV only can have an IC within the normal range. A recent cross-sectional study found that patients with COPD of GOLD stage 1 had VC and IC within the normal ranges, but their RV and FRC were increased. ${ }^{29}$ Thus, we analyzed longitudinal changes in both RV/TLC and IC/TLC in order to capture evidence of early changes in lung hyperinflation.

Since COPD is characterized by a progressive decline in $\mathrm{FEV}_{1}$ and functional capacity, we presumed that RV/ TLC would increase and IC/TLC would decrease over time in COPD patients. A prospective study performed some decades ago showed that RV, TLC, and RV/TLC significantly increased over a period of 4 years among smokers, although the sample size was very small and they were non-COPD patients. ${ }^{30} \mathrm{IC}$ and IC/TLC have also been shown to decrease over time in COPD patients. ${ }^{31,32}$ However, our results did not fully support these previous findings: while the IC/ TLC ratio decreased over time, the RV/TLC ratio did not increase. Rather, the RV/TLC ratio decreased by $0.35 \%$ / year. In accordance with this trend in the RV/TLC ratio, the $\mathrm{VC} / \mathrm{TLC}$ ratio increased over time.

The decline in lung volumes in our results could be explained by respiratory muscle dysfunction leading to insufficient inspiration. ${ }^{33}$ However, it is difficult to explain the decline in RV/TLC and increase in VC/TLC based only on respiratory muscle dysfunction. Another possible explanation is the effect of selection bias. For a more reliable longitudinal analysis, we included patients who were followed-up for 5 years or more. Therefore, less severe patients may have been included, while more severe patients died early, and this selection bias may have brought the intriguing trend in lung hyperinflation. However, the baseline $\mathrm{FEV}_{1}$ of patients in this study was $1.70 \pm 0.53 \mathrm{~L}$, and they had an overall decline in $\mathrm{FEV}_{1}$ at a rate of $29.4 \mathrm{~mL} /$ year. Since this $\mathrm{FEV}_{1}$ decline rate does not substantially differ from those recently reported in large-scale prospective studies, we believe that the results of our study are not simply due to less severity of disease. , $34-36^{5}$

In addition, our finding may result from the possible variability in measuring lung volumes. However, we performed plethysmographic lung volume measurements in qualified laboratories, and there was a quality assurance and feedback program when this cohort study was initiated. Nevertheless, we cannot exclude the variability in lung volume measurement as a possible source of bias. Therefore, further studies should examine whether our findings can be reproduced in other COPD cohorts.

On an individual level, the rate of change in RV/TLC was particularly variable, ranging from -4.2 to $2.8 \%$ /year. Considering a previous study that reported a minimal important difference of RV/TLC to be between $-2.8 \%$ and $-4.0 \%$, the range of the annual rate of change in RV/TLC in our study seems considerable. ${ }^{37}$ Interestingly, only $40 \%$ of the patients showed gradual increases in RV/TLC over time. These patients demonstrated more frequent exacerbations and a greater $\mathrm{FEV}_{1}$ decline compared to the remaining $60 \%$ of the patients who had shown gradual decreases in RV/ TLC. The rate of change in RV and TLC themselves also differed significantly between these two groups. However, the subgroup with a progressive increase in RV/TLC and a faster $\mathrm{FEV}_{1}$ decline had no definite baseline characteristics that were predictive. 
The single significant factor associated with a change in RV/TLC was exacerbation. Patients who had frequent exacerbations showed a significant increase in RV/TLC. They also had a faster decline in IC/TLC. That is, frequent exacerbations were associated with the progression in static lung hyperinflation. These findings are similar to those of previous studies that also found a relationship between frequent exacerbations and a rapid decline in $\mathrm{FEV}_{1},{ }^{5,38-40}$ Therefore, the frequent exacerbation phenotype of COPD may have common features, such as a rapid decline in lung function and progression in lung hyperinflation. ${ }^{41}$

Our study has several limitations. First, due to the design of this observational cohort study, this study could not address the precise effect of pharmacotherapy on the longitudinal changes in lung volumes and hyperinflation. Although pharmacotherapy with inhalers was shown to have no effect on improving the change in lung hyperinflation, this finding may result from unidentified confounding factors, which we were unable to assess and include in our analysis model. Additionally, more severe and symptomatic patients may have been prescribed more inhalers, resulting in a bias by indication. Second, this cohort study only included Asian patients and most of the patients were male with GOLD stage II or III COPD. This could have introduced selection bias. In particular, the low proportion of female patients in this study limits generalization of the results. Third, as we used a mixed-effect linear regression for this study, this may have oversimplified the trend of changes into a linear model. Our analysis could not accurately account for a more complex trend in lung volumes in individual patients. Fourth, there may have been overuse of inhaled corticosteroids because $~ 80 \%$ of the patients were prescribed inhaled corticosteroids during follow-up. Fifth, this cohort study did not include healthy aging individuals as a control group. If the trajectories of change in lung volumes could be compared between COPD patients and healthy individuals, this would provide more robust results. Finally, variability in measuring lung volumes as described earlier may have occurred. Despite these limitations, this study has value, in that, to our knowledge, it is the first to present longitudinal data, which were acquired over an extended period, from annual plethysmographic lung volume measurements.

\section{Conclusion}

The rates of change in RV/TLC and IC/TLC, as indicators of lung hyperinflation, were highly variable in COPD patients. Frequent exacerbations were associated with progression of lung hyperinflation over time, as determined by changes in $\mathrm{RV} / \mathrm{TLC}$ and IC/TLC. A progressive increase in RV/TLC over time was significantly associated with a faster decline in $\mathrm{FEV}_{1}$.

\section{Acknowledgments}

The authors thank Yeon-Mok Oh and Sang-Do Lee (Department of Pulmonary and Critical Care Medicine and Clinical Research Center for Chronic Obstructive Airway Diseases, Asan Medical Center, University of Ulsan College of Medicine, Seoul, Republic of Korea) and all the investigators of participating centers in the KOLD cohort. The KOLD cohort was supported by a grant from the Korea Healthcare Technology R\&D Project, Ministry for Health, Welfare and Family Affairs, Republic of Korea (A102065).

\section{Disclosure}

The authors report no conflicts of interest in this work.

\section{References}

1. Raherison C, Girodet PO. Epidemiology of COPD. Eur Respir Rev. 2009;18(114):213-221.

2. Rennard SI, Drummond MB. Early chronic obstructive pulmonary disease: definition, assessment, and prevention. Lancet. 2015; 385(9979):1778-1788.

3. Fletcher C, Peto R. The natural history of chronic airflow obstruction. BMJ. 1977;1(6077):1645-1648.

4. Lange P, Celli B, Agusti A, et al. Lung-function trajectories leading to chronic obstructive pulmonary disease. $N$ Engl J Med. 2015;373(2): 111-122.

5. Vestbo J, Edwards LD, Scanlon PD, et al. Changes in forced expiratory volume in 1 second over time in COPD. $N$ Engl J Med. 2011; 365(13):1184-1192.

6. O'Donnell DE, Laveneziana P. Physiology and consequences of lung hyperinflation in COPD. Eur Respir Rev. 2006;15(100):61-67.

7. O'Donnell DE, Guenette JA, Maltais F, Webb KA. Decline of resting inspiratory capacity in COPD: the impact on breathing pattern, dyspnea, and ventilatory capacity during exercise. Chest. 2012;141(3): 753-762.

8. Zaman M, Mahmood S, Altayeh A. Low inspiratory capacity to total lung capacity ratio is a risk factor for chronic obstructive pulmonary disease exacerbation. Am J Med Sci. 2010;339(5):411-414.

9. Casanova C, Cote C, de Torres JP, et al. Inspiratory-to-total lung capacity ratio predicts mortality in patients with chronic obstructive pulmonary disease. Am J Respir Crit Care Med. 2005;171(6):591-597.

10. Viegi G, Pistelli F, Sherrill DL, Maio S, Baldacci S, Carrozzi L. Definition, epidemiology and natural history of COPD. Eur Respir J. 2007;30(5):993-1013.

11. Park TS, Lee JS, Seo JB, et al; KOLD Study Group. Study design and outcomes of Korean obstructive lung disease (KOLD) cohort study. Tuberc Respir Dis (Seoul). 2014;76(4):169-174.

12. Vestbo J, Hurd SS, Agusti AG, et al. Global strategy for the diagnosis, management, and prevention of chronic obstructive pulmonary disease: GOLD executive summary. Am J Respir Crit Care Med. 2013; 187(4):347-365.

13. Oh YM, Jeong BH, Woo SY, et al; KOLD Study Group. Association of plasma adipokines with chronic obstructive pulmonary disease severity and progression. Ann Am Thorac Soc. 2015;12(7):1005-1012.

14. Miller MR, Hankinson J, Brusasco V, et al. Standardisation of spirometry. Eur Respir J. 2005;26(2):319-338.

15. Wanger J, Clausen JL, Coates A, et al. Standardisation of the measurement of lung volumes. Eur Respir J. 2005;26(3):511-522. 
16. Criee CP, Sorichter S, Smith HJ, et al. Body plethysmography-its principles and clinical use. Respir Med. 2011;105(7):959-971.

17. Choi JK, Paek D, Lee JO. Normal predictive values of spirometry in Korean population. Tuberc Respir Dis. 2005;58(3):230-242.

18. Song EH, Oh YM, Hong SB, et al. Selection of reference equations for lung volumes and diffusing capacity in Korea. Tuberc Respir Dis. 2006;61(3):218-226.

19. Quanjer PH, Tammeling GJ, Cotes JE, Pedersen OF, Peslin R, Yernault JC. Lung volumes and forced ventilatory flows. Report working party standardization of lung function tests, European Community for steel and coal. Official statement of the European Respiratory Society. Eur Respir J Suppl. 1993;16:5-40.

20. Global Initiative for Chronic Obstructive Lung Disease (GOLD) [webpage on the Internet]. Global Strategy for the Diagnosis, Management, and Prevention of Chronic Obstructive Lung Disease [Updated 2016]. Available from: http://goldcopd.org/global-strategy-diagnosismanagement-prevention-copd-2016. Accessed November 14, 2016.

21. Wedzicha JA, Seemungal TA. COPD exacerbations: defining their cause and prevention. Lancet. 2007;370(9589):786-796.

22. Fitzmaurice GM, Ravichandran C. A primer in longitudinal data analysis. Circulation. 2008;118(19):2005-2010.

23. Marin JM, Carrizo SJ, Gascon M, Sanchez A, Gallego B, Celli BR. Inspiratory capacity, dynamic hyperinflation, breathlessness, and exercise performance during the 6-minute-walk test in chronic obstructive pulmonary disease. Am J Respir Crit Care Med. 2001;163(6): 1395-1399.

24. Klooster K, ten Hacken NH, Hartman JE, Sciurba FC, Kerstjens HA, Slebos DJ. Determining the role of dynamic hyperinflation in patients with severe chronic obstructive pulmonary disease. Respiration. 2015; 90(4):306-313.

25. Satake M, Shioya T, Uemura S, et al. Dynamic hyperinflation and dyspnea during the 6-minute walk test in stable chronic obstructive pulmonary disease patients. Int J Chron Obstruct Pulmon Dis. 2015; 10:153-158.

26. Thomas M, Decramer M, O'Donnell DE. No room to breathe: the importance of lung hyperinflation in COPD. Prim Care Respir J. 2013; 22(1):101-111.

27. Ramon MA, Ferrer J, Gimeno-Santos E, et al; PAC-COPD Study Group. Inspiratory capacity-to-total lung capacity ratio and dyspnoea predict exercise capacity decline in COPD. Respirology. 2016;21(3): 476-482.

28. French A, Balfe D, Mirocha JM, Falk JA, Mosenifar Z. The inspiratory capacity/total lung capacity ratio as a predictor of survival in an emphysematous phenotype of chronic obstructive pulmonary disease. Int J Chron Obstruct Pulmon Dis. 2015;10:1305-1312.
29. Deesomchok A, Webb KA, Forkert L, et al. Lung hyperinflation and its reversibility in patients with airway obstruction of varying severity. COPD. 2010;7(6):428-437.

30. Corbin RP, Loveland M, Martin RR, Macklem PT. A four-year follow-up study of lung mechanics in smokers. Am Rev Respir Dis. 1979; 120(2):293-304.

31. Cortopassi F, Celli B, Divo M, Pinto-Plata V. Longitudinal changes in handgrip strength, hyperinflation, and 6-minute walk distance in patients with COPD and a control group. Chest. 2015;148(4):986-994.

32. Celli BR, Decramer M, Lystig T, Kesten S, Tashkin DP. Longitudinal inspiratory capacity changes in chronic obstructive pulmonary disease. Respir Res. 2012;13:66.

33. Orozco-Levi M. Structure and function of the respiratory muscles in patients with COPD: impairment or adaptation? Eur Respir J Suppl. 2003:46:41s-51s.

34. Vestbo J, Anderson JA, Brook RD, et al; SUMMIT Investigators. Fluticasone furoate and vilanterol and survival in chronic obstructive pulmonary disease with heightened cardiovascular risk (SUMMIT): a double-blind randomised controlled trial. Lancet. 2016;387(10030): $1817-1826$.

35. Tashkin DP, Celli B, Senn S, et al. A 4-year trial of tiotropium in chronic obstructive pulmonary disease. $N$ Engl J Med. 2008;359(15): 1543-1554.

36. Celli BR, Thomas NE, Anderson JA, et al. Effect of pharmacotherapy on rate of decline of lung function in chronic obstructive pulmonary disease: results from the TORCH study. Am J Respir Crit Care Med. 2008;178(4):332-338.

37. Hartman JE, Ten Hacken NH, Klooster K, Boezen HM, de Greef MH, Slebos DJ. The minimal important difference for residual volume in patients with severe emphysema. Eur Respir J. 2012; 40(5):1137-1141.

38. Kanner RE, Anthonisen NR, Connett JE. Lower respiratory illnesses promote $\mathrm{FEV}_{1}$ decline in current smokers but not ex-smokers with mild chronic obstructive pulmonary disease: results from the lung health study. Am J Respir Crit Care Med. 2001;164(3):358-364.

39. Donaldson GC, Seemungal TA, Bhowmik A, Wedzicha JA. Relationship between exacerbation frequency and lung function decline in chronic obstructive pulmonary disease. Thorax. 2002;57(10):847-852.

40. Halpin DM, Decramer M, Celli B, Kesten S, Liu D, Tashkin DP. Exacerbation frequency and course of COPD. Int J Chron Obstruct Pulmon Dis. 2012;7:653-661.

41. Wedzicha JA, Brill SE, Allinson JP, Donaldson GC. Mechanisms and impact of the frequent exacerbator phenotype in chronic obstructive pulmonary disease. BMC Med. 2013;11:181.
International Journal of COPD

\section{Publish your work in this journal}

The International Journal of COPD is an international, peer-reviewed journal of therapeutics and pharmacology focusing on concise rapid reporting of clinical studies and reviews in COPD. Special focus is given to the pathophysiological processes underlying the disease, intervention programs, patient focused education, and self management protocols.

\section{Dovepress}

This journal is indexed on PubMed Central, MedLine and CAS. The manuscript management system is completely online and includes a very quick and fair peer-review system, which is all easy to use. Visit http://www.dovepress.com/testimonials.php to read real quotes from published authors. 